\title{
REVIEW
}

\section{Antioxidant Therapies for Acute Spinal Cord Injury}

\author{
Edward D. Hall, 1,2,3 \\ ${ }^{I}$ Spinal Cord \& Brain Injury Research Center, University of Kentucky College of Medicine, Biomedical Biological Science \\ Research Building, Lexington, Kentucky 40506; ${ }^{2}$ Neurotrauma Research, Anatomy \& Neurobiology, Neurology, Neurosurgery and \\ Physical Medicine \& Rehabilitation, University of Kentucky Chandler Medical Center, Lexington, Kentucky 40506; and ${ }^{3} 741$ S. \\ Limestone St, Biomedical \& Biological Science Research Building 483, Lexington, Kentucky 40536-0509
}

\begin{abstract}
Summary: One of the most investigated molecular mechanisms involved in the secondary pathophysiology of acute spinal cord injury (SCI) is free radical-induced, iron-catalyzed lipid peroxidation (LP) and protein oxidative/nitrative damage to spinal neurons, glia, and microvascular cells. The reactive nitrogen species peroxynitrite and its highly reactive free radicals are key initiators of LP and protein nitration in the injured spinal cord, the biochemistry, and pathophysiology of which are first of all reviewed in this article. This is followed by a presentation of the antioxidant mechanistic approaches and pharmacological compounds that have been shown to have neuroprotective properties in preclinical SCI models. Two of
\end{abstract}

these, which act by inhibition of LP, are high-dose treatment with the glucocorticoid steroid methylprednisolone (MP) and the nonglucocorticoid 21-aminosteroid tirilazad, have been demonstrated in the multicenter NASCIS clinical trials to produce at least a modest improvement in neurological recovery when administered within the first 8 hours after SCI. Although these results have provided considerable validation of oxidative damage as a clinically practical neuroprotective target, there is a need for the discovery of safer and more effective antioxidant compounds for acute SCI. Key Words: Spinal cord injury, free radicals, lipid peroxidation, peroxynitrite, antioxidants, neuroprotection.

\section{INTRODUCTION}

One of the best validated secondary injury mechanisms in acute spinal cord injury (SCI) concerns the posttraumatic generation of reactive oxygen species (ROS) and their resulting oxygen free radical-induced oxidative damage. Indeed, the only evidence from clinical trials to date that supports the potential for an acute pharmacological neuroprotective effect in SCI involves two compounds that appear to work by interference with oxidative damage and the process of free radical-induced, iron-catalyzed lipid peroxidation (LP), in particular. This review will present the basics of the biochemistry of ROS and free radical generation, and the oxidative damage, evidence for its involvement in the biochemistry and pathophysiology of acute SCI and relationship to other secondary injury mechanisms, and the preclinical and clinical pharmacology of antioxidant neuroprotection.

Electronic supplementary material The online version of this article (doi:10.1007/s13311-011-0026-4) contains supplementary material, which is available to authorized users.

Address correspondence and reprint requests to: Edward D. Hall, Ph.D., 741 S. Limestone St, Biomedical Science Research Building 483, Lexington, KY 40536-0509. E-mail: edhall@uky.edu.

\section{CHEMISTRY OF FREE RADICAL PRODUCTION, LIPID PEROXIDATION, AND MECHANISMS FOR ITS PHARMACOLOGICAL INHIBITION}

The chemistry of free radical formation and LP has been previously discussed in a prior review of "AntiAntioxidant Therapies for Traumatic Brain Injury," an article recently published in this journal [1]. However, some updated portions of that article are re-presented here to provide the needed background for the discussion of oxidative damage and its prevention in the context of acute SCI.

\section{Superoxide radical}

In the injured spinal cord, a number of sources of the primordial free radical superoxide $\left(\mathrm{O}_{2}{ }^{\circ}\right)$ may be operative within the first minutes and hours after injury including the arachidonic acid cascade (i.e., by product of prostaglandin synthase and 5-lipoxygenase activity), either enzymatic (by-product of monoamine oxidase-B activity), or autooxidation of biogenic amine neurotransmitters (e.g., dopamine, norepinephrine, 5-hydroxytryptamine), "mitochondrial leak," xanthine oxidase activity, and the oxidation of extravasated hemoglobin. Activated microglia 
and infiltrating neutrophils and macrophages provide additional sources of $\mathrm{O}_{2}{ }^{--}$radicals.

Superoxide, which is formed by the single electron reduction of oxygen, may act as either an oxidant or reductant. Although $\mathrm{O}_{2}{ }^{--}$itself is reactive, its direct oxidative reactivity toward biological substrates in aqueous environments is relatively weak. In fact, its tendency to give up its unpaired electron (i.e., acting as a reductant) gives it the potential to act as an anti-oxidant instead of an oxidant. Moreover, once formed, $\mathrm{O}_{2}{ }^{-}$ undergoes spontaneous dismutation to form $\mathrm{H}_{2} \mathrm{O}_{2}$ in a reaction that is markedly accelerated by the enzyme superoxide dismutase: $\mathrm{O}_{2-}{ }^{-}{ }^{-}+\mathrm{O}_{2}{ }^{-}+2 \mathrm{H}^{+} \rightarrow \mathrm{H}_{2} \mathrm{O}_{2}+\mathrm{O}_{2}$ [2]. In solution, $\mathrm{O}_{2}{ }^{-}$actually exists in equilibrium with the hydroperoxyl radical $\left(\mathrm{HO}_{2}{ }^{\circ}\right): \mathrm{O}_{2}{ }^{-}+\mathrm{H}^{+} \rightarrow \mathrm{HO}_{2}{ }^{\bullet}$, which is considerably more lipid soluble and is a far more powerful oxidizing or reducing agent. Because the $\mathrm{pKa}$ of the $\mathrm{O}_{2}{ }^{-} / \mathrm{HO}_{2} \bullet$ is 4.8 , as the $\mathrm{pH}$ of a solution falls (i.e., tissue acidosis), the equilibrium between $\mathrm{O}_{2}{ }^{-}$and $\mathrm{HO}_{2}{ }^{\circ}$ shifts in favor of $\mathrm{HO}_{2}{ }^{\circ}$, which is much more reactive than $\mathrm{O}_{2}{ }^{--}$particularly toward lipids.

\section{Iron-dependent hydroxyl radical formation}

The central nervous system (CNS), including the spinal cord, is an extremely rich source of iron and its regional distribution varies in parallel with the sensitivity of various regions to oxidative damage [3]. Under normal circumstances, low molecular weight forms of redox active iron in the spinal cord are maintained at extremely low levels. In plasma, the iron transport protein transferrin tightly binds iron in the ferric $\left(\mathrm{Fe}^{+++}\right)$form. Intracellularly, $\mathrm{Fe}^{+++}$is sequestered by the iron storage protein ferritin. Although both ferritin and transferrin have very high affinity for iron at neutral $\mathrm{pH}$, and effectively maintain iron in a noncatalytic state [2], both proteins readily give up their iron at $\mathrm{pH}$ values of 6.0 or less, which is a level of acidosis that has been shown to be reached in the injured spinal cord. In the case of ferritin, its iron can also be released by reductive mobilization by $\mathrm{O}_{2}{ }^{-}$. Once iron is released from ferritin or transferrin, it can actively catalyze oxygen radical reactions. Therefore, within the traumatized spinal tissue, where $\mathrm{pH}$ is typically lowered, conditions are favorable for the potential release of iron from storage proteins [2].

A second source of catalytically active iron is hemoglobin. Hemorrhage resulting from mechanical trauma releases hemoglobin, as well as other bloodborne molecules, into the injured tissue. Although hemoglobin itself has been reported to stimulate oxygen radical reactions, it is more likely that iron released from hemoglobin is responsible for hemoglobin-mediated oxidative damage $[4,5]$. Iron is released from hemoglobin by $\mathrm{H}_{2} \mathrm{O}_{2}$ or by lipid hydroperoxides ( $\mathrm{LOOH}$; see as follows) [16], and this release is further enhanced as the $\mathrm{pH}$ falls to 6.5 or below.
Free iron or iron chelates participate in free radical reactions at two levels. The spontaneous oxidation (auto-oxidation) of ferrous iron $\left(\mathrm{Fe}^{++}\right)$results in the formation of $\mathrm{O}_{2}{ }^{\cdot-}$ [2]: $\mathrm{Fe}^{++}+\mathrm{O}_{2} \rightarrow \mathrm{Fe}^{+++}+\mathrm{O}_{2}{ }^{\cdot}$. Secondly, $\mathrm{Fe}^{++}$is also oxidized in the presence of $\mathrm{H}_{2} \mathrm{O}_{2}$ to form hydroxyl radical $(\cdot \mathrm{OH})$ (Fenton reaction): $\mathrm{Fe}^{++}+$ $\mathrm{H}_{2} \mathrm{O}_{2} \rightarrow \mathrm{Fe}^{+++}+\cdot \mathrm{OH}+\mathrm{OH}^{-}$.

\section{Peroxynitrite}

Nearly 20 years ago, Beckman [6] introduced the theory that the principal ROS involved in producing tissue injury in a variety of neurological disorders is the "reactive nitrogen species" (RNS) peroxynitrite (PN), which is formed by the combination of nitric oxide synthase (NOS)-generated nitric oxide ( $\cdot \mathrm{NO})$ radical and $\mathrm{O}_{2}{ }^{-}$as follows: $\mathrm{O}_{2}{ }^{-}+\cdot \mathrm{NO} \rightarrow \mathrm{ONOO}^{-}$. Peroxynitritemediated oxidative damage is actually caused by PN decomposition products that possess potent free radical characteristics. These are formed in 1 of 2 ways. The first involves the protonation of $\mathrm{PN}$ to form peroxynitrous acid (ONOOH), which can undergo homolytic decomposition to form the highly reactive nitrogen dioxide radical $\left(\cdot \mathrm{NO}_{2}\right)$ and $\mathrm{OH} ;\left(\mathrm{ONOOH} \rightarrow \cdot \mathrm{NO}_{2}+\right.$ $\cdot \mathrm{OH})$. Perhaps more important in the physiological context, PN will react with carbon dioxide to form nitrosoperoxocarbonate $\left(\mathrm{ONOOCO}_{2}\right)$, which can decompose into $\cdot \mathrm{NO}_{2}$ and carbonate radical $\left(\cdot \mathrm{CO}_{3}\right)$; $\left(\mathrm{ONOOCO}_{2} \rightarrow \cdot \mathrm{NO}_{2}+\cdot \mathrm{CO}_{3}\right)$. FIG. 1 summarizes this biochemistry of free radical formation as it relates to acute SCI.

Each of the PN-derived radicals $\left(\cdot \mathrm{OH}, \cdot \mathrm{NO}_{2}\right.$, and $\cdot \mathrm{CO}_{3}$ ) can initiate LP cellular damage by abstraction of an electron from a hydrogen atom bound to an allylic carbon in polyunsaturated fatty acids or can cause protein carbonylation by reaction with susceptible amino acids (e.g., lysine, cysteine, arginine). Additionally, $\cdot \mathrm{NO}_{2}$ can nitrate the 3-position of tyrosine residues in proteins; 3nitrotyrosine (3-NT) is a specific footprint of PN-induced cellular damage. Recent work strongly suggests that PN is a major contributor to secondary oxidative tissue damage in the injured spinal cord and compounds that scavenge either PN or its derived free radicals are neuroprotective (see as follows).

\section{Lipid peroxidation}

The process of LP involves three chemical reaction phases: initiation, propagation, and fragmentation. Initiation of LP occurs when a free radical species $(\mathrm{R} \bullet)$ oxidatively attacks and removes a hydrogen atom (including its single electron) from an allylic carbon (carbon surrounded by two adjacent carbons via double bonds) of a polyunsaturated fatty acid (LH). In the process $(\mathrm{LH}+\mathrm{R} \bullet \rightarrow \mathrm{L} \bullet+\mathrm{RH})$, the initiating radical is quenched by receipt of an electron (hydrogen) from the polyunsaturated fatty acid. However, this converts the 


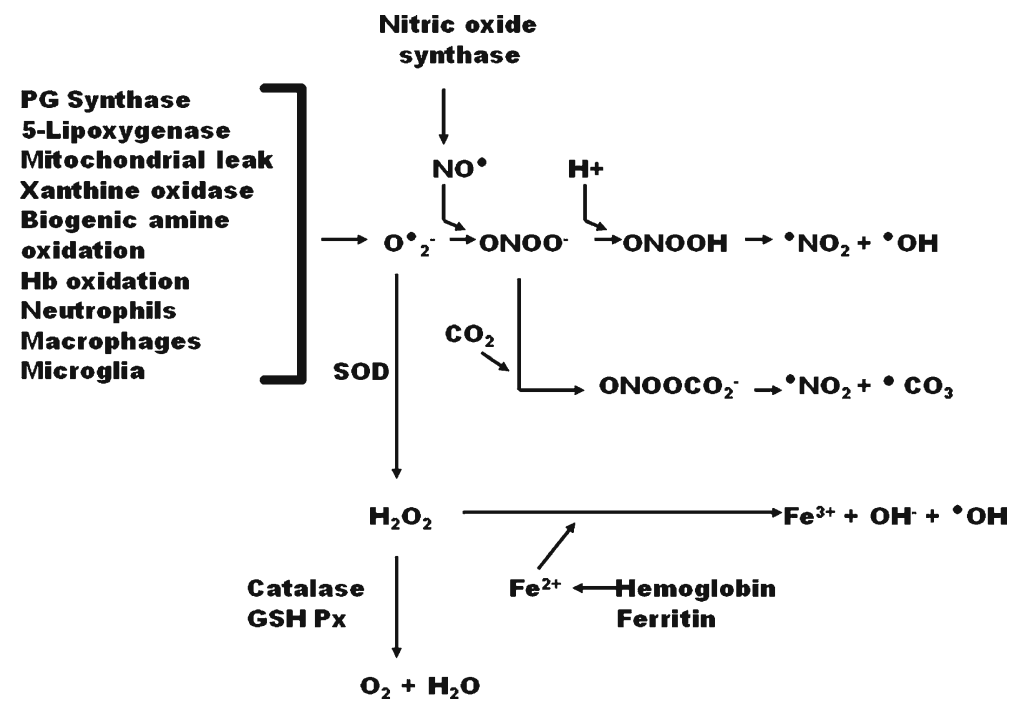

FIG. 1. Biochemistry of oxygen radical formation via the peroxynitrite pathway and the dismutation/Fenton reaction pathway. Nomenclature: $\mathrm{CO}_{2}=$ carbon dioxide; $\bullet \mathrm{CO}_{3}=$ carbonate radical; $\mathrm{Fe}^{2+}=$ ferrous iron; $\mathrm{Fe}^{3+}=$ ferric iron; GSH PX $=$ glutathione peroxidase; $\mathrm{H}+=$ proton; $\mathrm{H}_{2} \mathrm{O}_{2}=$ hydrogen peroxide; $\mathrm{Hb}=$ hemoglobin; $\mathrm{NO} \bullet=$ nitric oxide or nitrogen monoxide; $\bullet \mathrm{NO}_{2}=$ nitrogen dioxide; $\mathrm{O}_{2}^{-}=$superoxide radical; $\bullet \mathrm{OH}^{-}=$hydroxyl radical; $\mathrm{ONOO}^{-}=$peroxynitrite anion; $\mathrm{ONOOCO}_{2}^{-}=$nitrosoperoxocarbonate; $\mathrm{ONOOH}=$ peroxynitrous acid; $\mathrm{PG}=$ prostaglandin; $\mathrm{SOD}=$ superoxide dismutase.

latter into a lipid or alkyl radical $(\mathrm{L} \bullet)$. In turn, this sets the stage for a series of chain-like propagation reactions that begin when the alkyl radical takes on a mole of oxygen $\left(\mathrm{O}_{2}\right)$ creating a lipid peroxyl radical $(\mathrm{LOO} \bullet ; \mathrm{L} \bullet+$ $\mathrm{O}_{2} \rightarrow$ LOO•). The LOO• radical then reacts with a neighboring $\mathrm{LH}$ within the membrane and steals its electron forming a $\mathrm{LOOH}$ and a second alkyl radical ( $\mathrm{L} \cdot$; $\mathrm{LOO} \bullet+\mathrm{LH} \rightarrow \mathrm{LOOH}+\mathrm{L} \bullet$.

Once LP begins, iron may participate in driving the process as $\mathrm{LOOH}$ decomposes by reactions catalyzed by either $\mathrm{Fe}^{++}$or $\mathrm{Fe}^{+++}$. In the case of $\mathrm{Fe}^{++}$, the reaction results in formation of a lipid alkoxyl radical (LO•; $\left.\mathrm{LOOH}+\mathrm{Fe}^{++} \rightarrow \mathrm{LO} \bullet+\mathrm{OH}^{-}+\mathrm{Fe}^{+++}\right)$. If, however, the reaction involves $\mathrm{Fe}^{+++}$, the $\mathrm{LOOH}$ is converted back into a lipid peroxyl radical $\left(\mathrm{LOOH}+\mathrm{Fe}^{+++} \rightarrow \mathrm{LOO} \bullet+\right.$ $\left.\mathrm{Fe}^{++}\right)$. Both of the reactions of $\mathrm{LOOH}$ with iron have acidic $\mathrm{pH}$ optima making them more likely to occur in an acidic environment, which as noted earlier has been shown to be present in injured spinal cord tissue due to a metabolic shift toward anaerobic glucose metabolism and the generation lactic acid [7, 8]. Either alkoxyl (LO) or peroxyl (LOO) radicals arising from $\mathrm{LOOH}$ decomposition by iron can initiate so-called lipid hydroperoxide-dependent lipid peroxidation resulting in "chain branching" reactions: $(\mathrm{LOO} \bullet+\mathrm{LH} \rightarrow \mathrm{LOOH}+$ $\mathrm{L} \bullet$ or $\mathrm{LO} \bullet+\mathrm{LH} \rightarrow \mathrm{LOH}+\mathrm{L} \bullet$ ).

Ultimately, the LP process leads to fragmentation or "scission" reactions in which the peroxidized polyunsaturated fatty acid (e.g., arachidonic acid) breaks down to give rise to the neurotoxic aldehydes 4-hydroxynonenal (4-HNE) or 2-propanal (acrolein). Although LP disrupts the normal phospholipid architecture of cellular and subcellular organellar membranes, the end-products of LP 4-HNE and acrolein can bind to proteins, damaging their structure and function. On the other hand, primary radical-mediated oxidative damage can also occur in proteins. For instance, iron-catalyzed, $\bullet \mathrm{OH}$ mechanisms can target certain basic amino acids (e.g., lysine, arginine, histidine) leading to the formation of "protein carbonyl" moieties. However, it should be noted that not all of the protein carbonyl that is measured analytically is due to primary protein oxidation, but also includes carbonyl containing 4-HNE and acrolein that is bound to proteins. Still another form of protein oxidative damage involves the oxidation of cysteine sulfhydryl groups, which can lead to the formation of abnormal disulfide bridges and changes in protein structure and function [2].

Nucleic acids (both DNA and RNA) are also susceptible to oxidative medication by inorganic and organic (i.e., lipid) radicals. The most common measure of this form of damage involves the measurement of guanine oxidation product 8-hydroxyguanine. In addition to interfering with DNA replication, transcription and mRNA translation, DNA oxidative damage also triggers DNA repair mechanisms that can greatly stress cellular function and survival. One such mechanism concerns the activation of poly-ADP ribose polymerase whose action can lead to severe depletion of cellular stores of adenosine triphosphate (ATP). In addition, DNA-protein cross linking can occur (e.g., thymine-tyrosine) [2]. However, compared to the numerous studies that have documented post-traumatic LP in SCI, very little examination of nucleic acid oxidation has occurred. 


\section{EVIDENCE OF FREE RADICAL FORMATION AND OXIDATIVE DAMAGE IN THE ACUTELY INJURED SPINAL CORD}

\section{Increased free radical formation}

Liu et al. [9] provided the most direct evidence of an increase in free radical formation in the injured spinal cord. First, they documented an increase in $\mathrm{O}_{2}{ }^{-}$ production in the injured spinal cord by microcannula perfusion with cytochrome $\mathrm{C}$, which reacts with $\mathrm{O}_{2}{ }^{--}$ forming reduced cytochrome $\mathrm{C}$, a well known approach for measuring $\mathrm{O}_{2}{ }^{\circ}$. Second, they used a combination of microdialysis, salicylate trapping methods, and analytical techniques to demonstrate an early increase in $\bullet \mathrm{OH}$ levels in the contused rat spinal cord [10]. Moreover, in other experiments in which they infused $\mathrm{Fe}^{++}$and $\mathrm{H}_{2} \mathrm{O}_{2}$ (Fenton's reagent) into the injured spinal cord in a quantity sufficient to produce levels of $\bullet \mathrm{OH}$, similar to what they measured after contusion SCI, they observed that the resulting histological damage was similar to what they documented after contusion injury [10]. Others have similarly shown that microinjection of $\mathrm{Fe}^{++}\left(\mathrm{FeCl}_{2}\right)$ into the cat spinal cord produces a histological lesion that is nearly indistinguishable from that produced by contusion SCI [11].

\section{Increased lipid peroxidation}

The first evidence of LP occurring in the experimentally injured spinal cord was provided by Milvy et al. [12] who demonstrated an increase free radical species by electron spin resonance spectrometry and in the levels of the LP product malondialdehyde (MDA) in the contused cat spinal cord by spectrofluorescent methods [13]. Subsequently, the present author's laboratory confirmed the early posttraumatic increase in MDA, along with an increase in cyclic guanosine monophosphate (cGMP) levels hypothesized to be due to the free radical and LOOH-induced activation of guanylate cyclase activation as early as $1 \mathrm{~h}$ post-SCI [14]. Others have confirmed that MDA levels increase in the first $2 \mathrm{~h}$ [15]. An increase in LP that appears in the injured cord within the first hour has also been evidenced in terms of a depletion of endogenous antioxidants, including ascorbic acid [16], alpha-tocopherol (also known as vitamin E) [17], glutathione [18], and ubiquinol-9 and ubiqunol-10 [19]. More contemporary immunohistochemical and immunoblotting methods have been recently used, which reveals an impressive increase in the levels of the LP-derived aldehydic breakdown products 4-HNE [2023] and acrolein [24, 25].

As noted earlier, free iron is an important catalyst for both $\cdot \mathrm{OH}$ generation and the propagation of LP reactions. Indeed, changes in free iron content in the injured spinal cord have been shown to correlate with the levels of LP products formed during the first hours after SCI [26].

\section{Increased protein oxidation}

Multiple laboratories have demonstrated an increase in protein oxidation products in the injured spinal cord using the dinitrophenylhydrazine (DNPH) trapping method, which reacts with the protein carbonyl groups found on lysine, arginine, and histidine residues due to iron-induced oxidation. Using immunoblotting techniques that identify DNPH-modified protein carbonyl moieties, an increase in protein oxidation has been documented by at least three laboratories [23, 27, 28]. However, it must be noted that the DNPH-based carbonyl assay does not distinguish between protein carbonyl groups produced by direct iron-driven amino acid oxidation and protein binding of LP-generated aldehydic breakdown products, which can also leave exposed carbonyl groups that can react with DNPH [2]. Thus, the protein carbonyl assay is both a measure of LP and direct protein oxidation.

\section{Increased peroxynitrite-mediated oxidative damage}

Increasing evidence suggests that PN plays at least an equal role with iron-induced Fenton chemistry as a source of damaging free radicals in the injured spinal cord. As explained earlier in this article, PN can produce LP and protein oxidative damage via its derived free radicals $\bullet \mathrm{OH}$, $\cdot \mathrm{NO}_{2}$, and $\bullet \mathrm{CO}_{3}$. However, the indictment of $\mathrm{PN}$ as a player in secondary damage in spinal cord tissue is derived from analytic or immunological measurements of $\bullet \mathrm{NO}_{2}$-mediated nitration of protein tyrosine residues (3-NT). Several laboratories have now documented an increase in 3-NT content in the injured spinal cord, beginning within the first hour in rat contusion SCI models [23, 28-31]. Using microdialysis, Liu et al. (31) have been able to estimate the levels of 3-NT produced in the contused spinal cord. This was followed by their demonstration that microcannula infusion of PN or the PN-generating compound 3morpholinosydnonimine (SIN-1) into the noninjured spinal cord in sufficient quantities to achieve the levels of PN and 3-NT observed in the contused spinal cord resulted in neuronal damage similar to that observed after SCI [3235]. The author's laboratory, using immunoblotting and immunohistochemical approaches, has shown that the temporal and spatial time courses of lipid peroxidative (4$\mathrm{HNE}$ ) and protein nitrative (3-NT) damage in the injured spinal cord are nearly identical, suggesting that $\mathrm{PN}$ is a major initiator of both forms of post-SCI oxidative damage. FIG. 2 displays the overlap of 4-HNE and 3-NT immunostaining during the first $72 \mathrm{~h}$ after SCI.

\section{INVOLVEMENT OF OXIDATIVE DAMAGE IN THE ACUTE PATHOPHYSIOLOGY OF SCI}

Free radicals and oxidative damage have been linked to a number of aspects of the secondary pathophysiology of acute SCI. Most notable among these are disruption of 


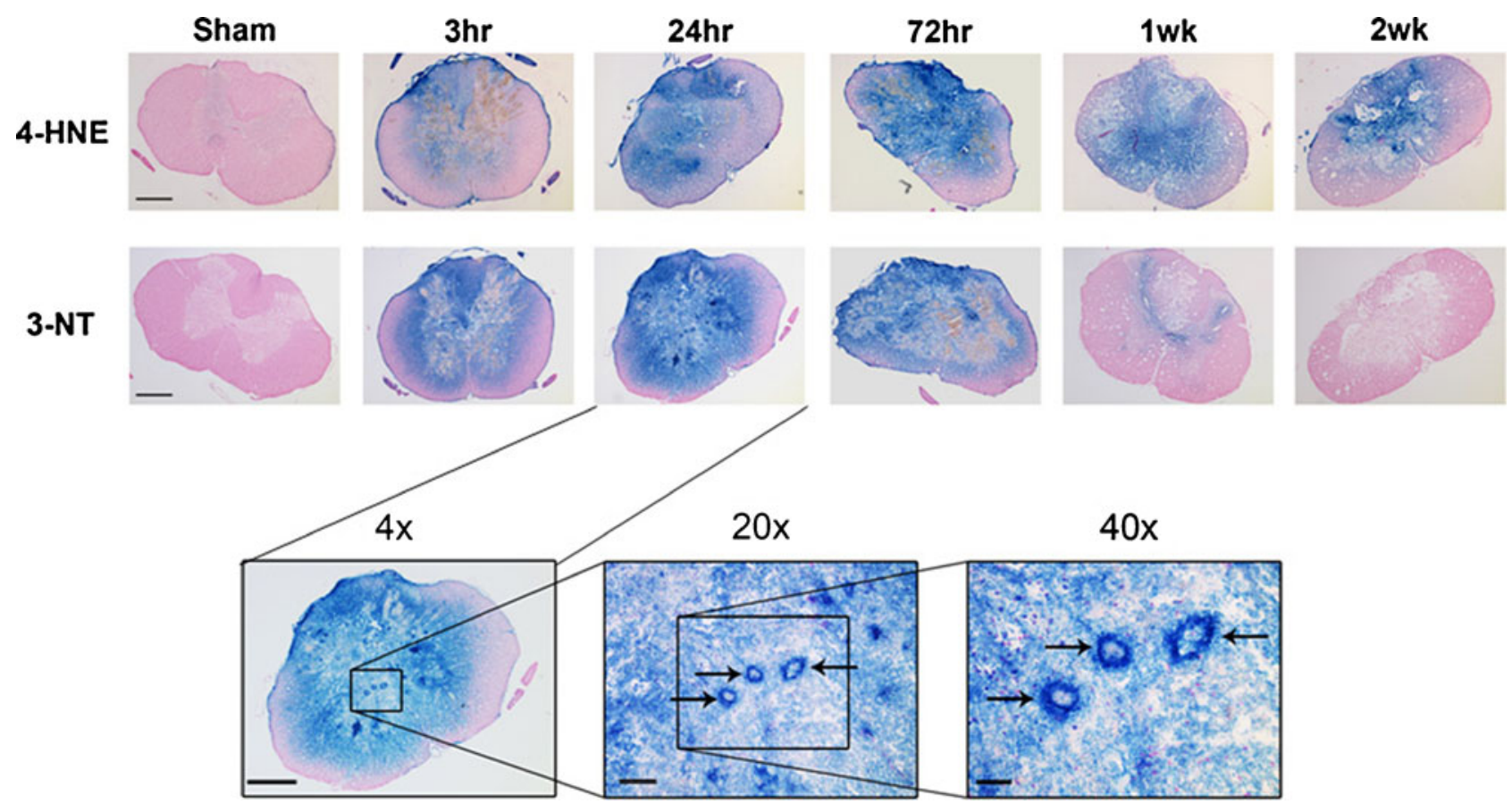

FIG. 2. (a) Representative examples showing the post-traumatic time course of oxidative damage as revealed by 3-nitrotyrosine (3-NT) and 4-hydroxynonenal (4-HNE) immunostaining. Images are representative coronal sections at the epicenter (T10) at 24 and $72 \mathrm{~h}$, and at 1 and 2 weeks post-injury. Adjacent sections from the same animal were stained for 3-NT and 4-HNE. All sections are counterstained with nuclear fast red. Sham animal showed minimal staining for both markers. By 3-h post injury, staining was substantially elevated, encompassing all of the gray matter and extending into the white matter. It peaked for 3-NT and 4-HNE around 24- to 72-h postinjury with only a small rim of white matter remaining unstained. By 1 week, 3-NT staining had nearly disappeared, whereas the elevation of 4HNE persisted throughout the gray matter out to at least 2-week post injury. Scale bar $=500 \mu \mathrm{m}$. (b) Higher power views of 3-NT oxidative damage in the injured spinal cord in the 24-h post-injury spinal cross section at 1-mm caudal to the epicenter, which shows intense oxidative damage staining of gray matter microvessels (arrows), as well as surrounding parenchymal elements, the same 24-h 3-NT cross section from (a). A collage of FIGS. 1 and 5, and for more detail see Carrico et al. [22], reproduced with permission.

spinal neuronal ion homeostasis, mitochondrial dysfunction, enhancement of glutamate-mediated excitotoxicity, and microvascular perfusion deficits.

\section{Role in disruption of ion homeostasis}

One of the most established components of posttraumatic SCI pathophysiology is the occurrence of massive disruptions in neuronal ionic physiology related to sodium $\left(\mathrm{Na}^{+}\right)$, potassium $\left(\mathrm{K}^{+}\right)$, calcium $\left(\mathrm{Ca}^{++}\right)$. Although the initial changes in ion distributions are triggered by mechanical depolarization, opening of voltage-dependent ion channels and release of excitatory neurotransmitters (e.g., glutamate and aspartate), oxidative membrane damage has been linked to subsequent exacerbations of ion homeostatic dysfunction. Perhaps most critical of these oxidative damage-enhanced ionic disturbances concerns the ability of ROS to increase intracellular $\mathrm{Ca}^{++}$overload due in large part to the sensitivity of the plasma and endoplasmic reticular membrane $\mathrm{Ca}^{++}$-ATPase (i.e., $\mathrm{Ca}^{++}$ pump) to LP-induced damage [36, 37]. Inhibition of this enzyme interferes with $\mathrm{Ca}^{++}$extrusion. Induction of LP in isolated synaptosomes has been demonstrated to rapidly increase $\mathrm{Ca}^{++}$uptake, which was blocked by antioxidant compounds, but not by $\mathrm{Ca}^{++}$channel blockers [38].
Similarly, LP-mediated oxidative inactivation of the membrane $\mathrm{Na}^{+} / \mathrm{K}^{+}$-ATPase [37] worsens intracellular $\mathrm{Na}{ }^{+}$ accumulation, which will then reverse the direction of the $\mathrm{Na}^{+} / \mathrm{Ca}^{++}$exchanger (anti-porter) and further exacerbate intracellular $\mathrm{Ca}^{++}$accumulation. Inhibition of $\mathrm{Na}^{+} / \mathrm{K}^{+}$ATPase has been repeatedly demonstrated in injured spinal cord tissue in parallel with an increase in LP products [14, 39].

\section{Role in mitochondrial dysfunction}

Mitochondrial dysfunction plays an especially critical role in the post-traumatic cell death cascade in the injured spinal cord. It is clear that this is directly related to the intracellular accumulation of $\mathrm{Ca}^{++}$ions, which compromise mitochondrial function and increase ROS production. Following SCI, there is a loss of mitochondrial homeostasis together with increased mitochondrial ROS production and LP-induced disruption of synaptic homeostasis [40-43]. Evidence has accumulated, which shows a particularly important ROS that is being formed by $\mathrm{Ca}^{++}$-stressed mitochondria is PN. Nitric oxide has been shown to be present in mitochondria derived from a mitochondrial NOS isoform $[44,45]$. Exposure of mitochondria to $\mathrm{Ca}^{++}$, which is 
known to cause them to become dysfunctional, leads to $\mathrm{PN}$ generation, which in turn triggers mitochondrial $\mathrm{Ca}^{++}$ release (i.e., limits the $\mathrm{Ca}^{++}$uptake or buffering capacity) [46]. Both PN forms, $\mathrm{ONOO}^{-}$and $\mathrm{ONOOCO}_{2}$, have been shown to deplete mitochondrial antioxidant stores and to cause protein nitration [47]. The relationship of PN generation to mitochondrial dysfunction in the injured spinal cord has been recently documented by studies that have shown the timing of post-SCI mitochondrial dysfunction (i.e., respiratory and $\mathrm{Ca}^{++}$buffering impairment) is correlated with an increase in PNinduced 3-NT and 4-HNE and protein carbonyl content in mitochondrial proteins [28]. The loss of mitochondrial function and the increase in oxidative damage markers, including 3-NT, is antagonized by early in vivo post-SCI treatment with the PN radical scavenger tempol [23]. Other studies have demonstrated that the exposure of normal CNS mitochondria to 4-HNE rapidly impairs their respiratory function and that spinal cord mitochondria are 10-fold more sensitive to this effect than brain mitochondria [48].

\section{Enhancement of glutamate-mediated excitotoxicity}

It is well known that glutamate-mediated excitotoxic mechanisms play an important role in secondary injury after SCI [49-52]. Also, the fact that there is a reciprocal link between the post-traumatic neurotoxicity of glutamate and free radical-induced oxidative damage is well established. First, the detrimental effect of LP on intracellular $\mathrm{Ca}^{++}$(e.g., $\mathrm{Ca}^{++}$permeabilities, extrusion mechanisms, and mitochondrial/endoplasmic reticular buffering) will act to increase glutamate-mediated postsynaptic excitotoxicity, which is largely mediated by intracellular $\mathrm{Ca}^{++}$overload. Second, free radical mechanisms have been demonstrated to potentiate glutamate release, an effect that is antagonized by free radical scavenging agents [53]. Third, the accumulation of LP products such as 4-HNE in synaptosomal membranes harvested from injured spinal cord tissue is associated with an impairment of synaptosomal glutamate uptake [21]. Additionally, it has been demonstrated in other in vitro studies that induction of LP in synaptosomes [54] or spinal neuronal cultures [55] impairs amino acid uptake mechanisms. Fourth, and most convincing in regard to the involvement of oxidative damage in excitotoxicity, is the finding that LP inhibitors have been shown to attenuate glutamate and N-methyl-D-aspartate (NMDA)-induced damage in neuronal cultures, confirming the involvement of LP in glutamate-mediated cell death [56].

\section{Impairment of microvascular perfusion}

Demopoulos et al. [57] in their seminal studies on post-SCI LP demonstrated that LP-associated injury includes early $(2-3 \mathrm{~h})$ damage to spinal microvascular endothelium in the form of crater formation, adherence of platelets and leukocytes, and microemboli coincident with a reduction in spinal cord white matter blood flow (SCBF). Pharmacological confirmation of the association of LP-induced spinal microvascular damage with a decrease in SCBF was provided by the present author who showed that pre-SCI treatment with high doses of the LP inhibitor, vitamin E or ascorbic acid, significantly attenuated the drop in white matter SCBF during the first 4-h postinjury [58]. Additionally, acute postinjury administration of LP inhibitors has been shown to prevent the progressive decline in SCBF, if administered within the first hour after SCI $[59,60]$.

\section{NEUROPROTECTIVE EFFECTS OF ANTIOXIDANT DRUGS IN SCI INJURY}

\section{Overview of antioxidant mechanistic approaches}

Based on the previously outlined steps involved in oxygen radical-induced oxidative damage, and LP in particular, a number of potential mechanisms for its inhibition are apparent. These fall into 4 general categories.

The first category includes compounds that inhibit the initiation of LP and other forms of oxidative damage by preventing the formation of ROS or RNS species. For instance, nitric oxide synthesis inhibitors by limiting $\bullet \mathrm{NO}$ production can limit PN formation. However, they also have the potential to interfere with the physiological roles for which $\bullet \mathrm{NO}$ is responsible, including antioxidant effects, due to its important role as a scavenger of lipid peroxyl radicals (e.g., LOO $\bullet \cdot+\mathrm{NO} \rightarrow$ LOONO) [61]. Another approach to blocking post-traumatic radical formation is the inhibition of the arachidonic acid cascade, during which the formation of $\mathrm{O}_{2}{ }^{--}$occurs as a by-product of prostaglandin synthase and 5-lipoxygenase biochemistry.

The second indirect LP inhibitory approach involves chemically scavenging the initiating radical species (e.g., $\mathrm{O}_{2}{ }^{\cdot-}, \cdot \mathrm{OH}, \cdot \mathrm{NO}_{2}, \cdot \mathrm{CO}_{3}$ ) before they have a chance to steal an electron from a polyunsaturated fatty acid and thus initiate LP. The use of pharmacologically administered SOD represents an example of this strategy. Another example concerns the use of the nitroxide antioxidant tempol, which has been shown to catalytically scavenge the PN-derived free radicals $\bullet \mathrm{NO}_{2}$ and $\cdot \mathrm{CO}_{3}$ [62]. In either case, a general limitation of these first two approaches is that they would be expected to have a short therapeutic window such that the inhibiting drugs would have to be administered rapidly to have a chance to interfere with the initial posttraumatic, free radical production that has been documented in SCI models $[10,63]$. Although it is believed that ROS and RNS production persists for some 
hours or days after injury, the major portion of inorganic nonlipid radical formation is an early event (often referred to as "free radical burst") that peaks too quickly to pharmacologically inhibit, unless the antioxidant compound is already on board when the injury occurs or is available for administration immediately thereafter.

In contrast to these indirect-acting antioxidant mechanisms, the third category involves stopping the chain reaction propagation of LP once it has begun. One way to accomplish this would be with a drug that can intercalate (i.e., insert itself) within the neural cell (e.g., neurons, vascular cells, glia) membranes among the phospholipids of the membrane bi-layer and physicochemically inhibiting membrane fluidity and the propagation of LP reactions by blocking the interaction of $\mathrm{LOO} \bullet$ and $\mathrm{LO} \bullet$ with adjacent polyunsaturated fatty acids. An example of this kind of antioxidant effect is seen with the administration of high doses of the glucocorticoid steroid MP detailed later in this review.

The fourth and most frequently demonstrated way to accomplish this is by directly scavenging $\mathrm{LOO} \bullet$ or $\mathrm{LO} \bullet$ radicals. The endogenous, and thus prototypical, scavenger of these lipid radicals is alpha-tocopherol (vitamin E [vit E]), which inhibits LP by donating an electron from its phenolic hydroxyl $(\mathrm{OH})$ moiety to quench a $\mathrm{LOO} \cdot$ radical. However, this scavenging process is only stoichiometric ( 1 vit $\mathrm{E}$ can only quench $1 \mathrm{LOO} \bullet$ ), and in the process vit $\mathrm{E}$ loses its antioxidant efficacy becoming a vit $\mathrm{E}$ radical $(\mathrm{LOO} \bullet+$ vit $\mathrm{E} \rightarrow \mathrm{LOOH}+$ vit $\mathrm{E} \bullet$ ). Although vit $\mathrm{E}^{-}$is relatively harmless, it also cannot scavenge another LOO until it is reduced back to its active form by receiving an electron from another endogenous reducing agent, such as ascorbic acid (vitamin C) or glutathione (GSH). Although this tripartite LOO antioxidant defense system (vit $\mathrm{E}$, vitamin $\mathrm{C}$, GSH) works fairly effectively in the absence of a major post-traumatic oxidative stress, studies have shown that each of these antioxidants is rapidly consumed during the early minutes and hours after SCI [16-18]. Thus, it has long been recognized that more effective pharmacological LOO and LO scavengers are needed than what endogenous biochemistry has provided. Furthermore, it is expected that compounds that could interrupt the LP process after it has begun would be able to exert a more practical neuroprotective effect (i.e., possess longer antioxidant therapeutic window).

\section{Prophylactic neuroprotection with high-dose vitamin $\mathbf{E}$}

As already mentioned, acute spinal cord compression injury in cats results in a rapid depletion of endogenous tissue vit $\mathrm{E}$ levels by $80 \%$ below the levels in noninjured spinal tissue by $4 \mathrm{~h}$ postinjury $[64,65]$, due to its rapid consumption during intense post-SCI LP reactions. On the other hand, high-dose oral vit E supplementation for 5 days prior to SCI acts to attenuate the progressive posttraumatic decrease in white matter SCBF [58] together with a significant enhancement in hind-limb motor function compared to non-vit $\mathrm{E}$ supplemented animals [66]. This effect has been replicated in a rat compression SCI model [67]. In contrast, vit E deficiency has been shown to increase post-SCI LP and to attenuate motor functional recovery [68]. However, despite these effects, the value of vit $\mathrm{E}$ as an acute treatment for $\mathrm{SCI}$ is limited by the fact that it require weeks to achieve a significant increase in parenchymal CNS tissue levels [69]. On the other hand, long-term, oral high-dose supplementation with vit $\mathrm{E}$ may provide effective prophylactic neuroprotection against SCI. Unfortunately, none of the experimental SCI studies have defined the dose response for prophylactic vit $\mathrm{E}$ neuroprotection. As a possible guide for human use of vit $\mathrm{E}$ supplementation to limit post-SCI neurological impairment, it has been shown that the dose required to lessen baseline LP product levels in human plasma after 20 weeks of daily supplementation is 800 I.U./day [70].

\section{Antioxidant neuroprotection with high-dose methylprednisolone therapy}

Increasing knowledge of the post-traumatic LP mechanism in the $1970 \mathrm{~s}$ and early $1980 \mathrm{~s}[57,71]$ prompted the search for a neuroprotective pharmacologic strategy aimed at antagonizing oxygen radical-induced LP in a safe and effective manner. Attention was focused on the hypothetical possibility that glucocorticoid steroids might be effective inhibitors of post-traumatic LP, based on their high lipid solubility and known ability to intercalate into artificial membranes between the hydrophobic polyunsaturated fatty acids of the membrane phospholipids and to thereby limit the propagation of LP chain reactions throughout the phospholipid bilayer [57, 7274]. The author's laboratory tested whether the early administration of high-dose glucocorticoid MP might be able to inhibit post-traumatic spinal cord LP. In an initial set of experiments in cats, it was observed that the administration of an intravenous bolus of MP could indeed inhibit post-traumatic LP in spinal cord tissue [73], but that the doses required for this effect were surprisingly high $(30 \mathrm{mg} / \mathrm{kg})$. Further experimental studies, also conducted in cat SCI models, showed that the $30 \mathrm{mg} / \mathrm{kg}$ dose of MP not only prevented LP, but in parallel, it inhibited post-traumatic spinal cord ischemia $[59,75]$ and supported aerobic energy metabolism (i.e., reduced lactate and improved ATP levels) [8, 76, 77], improved recovery of extracellular calcium (i.e., reduced intracellular overload) [75], and attenuated calpainmediated neurofilament degradation [77]. However, the central effect in this protective scenario is the inhibition of post-traumatic LP. With many of these therapeutic 
parameters (i.e., LP, secondary ischemia, aerobic energy metabolism), the dose response for MP follows a sharp U-shaped pattern. The neuroprotective and vasoprotective effect is partial with a dose of $15 \mathrm{mg} / \mathrm{kg}$, optimal at $30 \mathrm{mg} / \mathrm{kg}$, and fully diminished at $60 \mathrm{mg} / \mathrm{kg}$ [72].

The antioxidant neuroprotective action of MP is closely linked to the tissue pharmacokinetics of the drug $[8,72,78$, 79]. For instance, when MP tissue levels are at their peak following administration of a $30 \mathrm{mg} / \mathrm{kg}$ intravenous dose, lactate levels in the injured cord are suppressed. When tissue MP levels decline, spinal tissue lactate rises. However, the administration of a second dose $(15 \mathrm{mg} / \mathrm{kg}$ i.v.), at the point at which the levels after the first dose have declined by $50 \%$, acts to maintain the suppression of lactate seen at the peak of the first dose and to more effectively maintain ATP generation and energy charge and protect spinal cord neurofilaments from degradation $[8,77]$. This prompted the hypothesis that prolonged MP therapy might better suppress the secondary injury process and lead to better outcomes compared with the effects of a single, large intravenous dose. Indeed, subsequent experiments in a cat spinal injury model demonstrated that animals treated with MP using a 48-hour antioxidant dosing regimen improved recovery of motor function during a 4-week period [64, 80].

Although it is believed that much of the vaso- and neuroprotective effect of MP is indeed due to inhibition of LP, this glucocorticoid has also been reported to decrease oligodendroglial apoptosis in the injured rat spinal cord via a mechanism related to glucocorticoid receptor activation because a glucocorticoid receptor antagonist blocks the oligodendroglial protection [81]. It has also been proposed that some of the protective effects of MP may be due to its well-known antiinflammatory effects. However, those actions are seen at much lower doses than those required to protect the injured spinal cord via LP inhibitory effects [82].

\section{NASCIS II efficacy of 24-h high-dose MP}

The experimental studies with high-dose MP inspired the testing of its efficacy in human SCI in the second National Acute Spinal Cord Injury Study (NASCIS II) [83], even though an earlier NASCIS trial, which came to be known as NASCIS I, had failed to show any efficacy of lower MP doses when administered for a 10-day period [84, 85]. The NASCIS II trial compared 24-h dosing with MP vs placebo for the treatment of acute SCI. A priori trial hypotheses included the prediction that SCI patients treated within the first 8-h postinjury would respond better to pharmacotherapy than patients treated after $8 \mathrm{~h}$. Indeed, the results demonstrated the effectiveness of $24-\mathrm{h}$, intensive MP dosing $(30 \mathrm{mg} / \mathrm{kg}$ i.v. bolus plus a 23 -h infusion at $5.4 \mathrm{mg} / \mathrm{kg} / \mathrm{h}$ ) when treatment was initiated within $8 \mathrm{~h}$. A significant benefit was observed in individuals with both neurologically complete (i.e., plegic) and incomplete (i.e., paretic) injuries. Moreover, the functional benefits were sustained at 6-week, 6month, and 1-year follow-ups [83, 86-88]. The highdose regimen actually improved function below the level of the injury and lowered the level of the functional injury [87]. Subsequent to NASCIS II, 2 other groups of investigators in Japan [89] and France [90] reported successful replications of the therapeutic efficacy of the NASCIS II MP protocol in SCI patients.

Although predictable side effects of steroid therapy were noted in NASCIS II (including gastrointestinal bleeding, wound infections, and delayed healing), these were not significantly more frequent than those recorded in placebo-treated patients [83]. Another finding was the fact that delay in the initiation of MP treatment until after $8 \mathrm{~h}$ was actually associated with decreased neurological recovery [87]. Thus, treatment within the 8 -h window is beneficial, whereas dosing after $8 \mathrm{~h}$ can be detrimental for reasons that are discussed in detail elsewhere [82].

\section{Tirilazad: A 21-aminosteroid antioxidant devoid of glucocorticoid side effects}

Methylprednisolone is a potent glucocorticoid that possesses a number of glucocorticoid receptor-mediated anti-inflammatory and cytoprotective actions. Despite the possible role of these effects of MP in the injured spinal cord, the principal neuroprotective mechanism appears to be the inhibition of post-traumatic LP that is not mediated via glucocorticoid receptor-mediated activity [91-93]. This knowledge prompted the hypothesis that modifying the steroid molecule to enhance the anti-LP effect, while eliminating the glucocorticoid effects of the steriod would result in more targeted antioxidant therapy devoid of the typical side effects of steroid therapy. This led to the discovery and development of more potent steroidal LP inhibitors, the 21-aminosteroids or "lazaroids," which lack the glucocorticoid receptor-mediated side effects that limit the clinical use of high-dose MP. One of these, tirilazad (also known as U-74006F), was selected for development based on its beneficial effects in animal SCI models $[60,94,95]$.

\section{NASCIS III extension of high-dose MP \\ from 24- to 48-h and comparison with tirilazad}

The demonstrated efficacy of a 24-h dosing regimen of MP in human SCI in NASCIS II [83] and the discovery of tirilazad [91-93] prompted the conduct of NASCIS III $[96,97]$. In the NASCIS III trial, 3 groups of patients were evaluated. The first (active control) group was treated with the 24-h MP dosing regimen that had been previously shown to be effective in NASCIS II. The second group was also treated with MP, except that the duration of the MP infusion was prolonged to $48 \mathrm{~h}$. The purpose was to determine whether extension of the MP infusion from 24- to 48-h resulted in greater improve- 
ment in neurological recovery in acute SCI patients. The third group of patients was treated with a single $30 \mathrm{mg} / \mathrm{kg}$ intravenous bolus of MP followed by the 48-h administration of tirilazad. No placebo group was included because it was deemed ethically inappropriate to withhold at least the initial large bolus of MP. Another objective of the study was to ascertain whether treatment initiation within $3 \mathrm{~h}$ following injury was more effective than when therapy was delayed until 3- to 8-h post-SCI.

When the NASCIS III trial was complete, it was found that all 3 treatment arms produced comparable degrees of recovery when treatment was begun within the shorter 3$\mathrm{h}$ window. When the 24-h dosing of MP was begun more than $3 \mathrm{~h}$ post-SCI, recovery was poorer in comparison with the cohort treated within $3 \mathrm{~h}$ following SCI. However, in the 3- to 8-h post-SCI cohort, when MP dosing was extended to $48 \mathrm{~h}$, significantly better recovery was observed than with the 24-h dosing. In the comparable tirilazad cohort (3-8 $\mathrm{h}$ post-SCI), recovery was slightly but not significantly better than in the 24-h MP group, and it was poorer than in the 48-h MP group. These results showed that: 1) initiation of highdose MP treatment within the first $3 \mathrm{~h}$ is optimal; 2) the nonglucocorticoid tirilazad is as effective as 24-h MP therapy; and 3) if treatment is initiated more than $3 \mathrm{~h}$ post-SCI, extension of the MP dosing regimen is indicated from 24 to $48 \mathrm{~h}$. However, in comparison with the 24-h dosing regimen, significantly more glucocorticoid-related immunosuppression-based side effects were seen with more prolonged dosing (i.e., the incidence of severe sepsis and pneumonia significantly increased). In contrast, tirilazad showed no evidence of steroid-related side effects, suggesting that this nonglucocorticoid 21aminosteroid would be safer for extension of dosing beyond the 48-h limit used in NASCIS III [96, 97].

It should be noted that subsequent to the demonstration of significantly increased side effects of 48-h dosing with MP in NASCIS III, a controversy has developed concerning the risk-to-benefit ratio for MP in human SCI. For a more complete discussion of the pros and cons involved in this controversy and specific recommendations for MP use in acute SCI, the reader is referred elsewhere [82]. Moreover, Table 1 summarizes the design and results of NASCIS I, II, and III clinical trials.

\section{Efficacy of peroxynitrite scavengers in SCI models}

In view of the well-validated role of ROS, RNS, and oxygen radical-induced LP in the pathophysiology of posttraumatic secondary SCI, and the demonstrated benefits of LP inhibitors such as high-dose MP and tirilazad, it has been logical to pursue the development of improved antioxidant compounds that could more safely and effectively inhibit post-traumatic LP. Accumulating evidence strongly suggests that the most important reactive oxygen species in acute SCI is probably PN [30, 34]. Consistent with this view, several compounds that scavenge either PN, including uric acid [98] and the PN decomposition catalyst $5,10,15,20$-tetrakis (4-sulfanatophenyl) porphyrin iron III cloride (FeTSPP) [99], or that scavenger PN-derived free radicals such as tempol, a catalytic scavenger of $\mathrm{PN}$-derived $\cdot \mathrm{NO}_{2}$ and $\cdot \mathrm{CO}_{3}[62,100-102]$ have been reported to have neuroprotective and/or neurological recovery-promoting effects in SCI models. A major mechanism of the protective effect of tempol appears to be preservation of spinal cord mitochondrial function from post-traumatic PN-mediated impairment [101]. FIG. 3 displays the effects of early (15 minutes) post-SCI tempol administration on mitochondrial oxidative damage in rat thoracic spinal cord tissue subjected to contusion SCI $24 \mathrm{~h}$ earlier [105].

Two broad spectrum antioxidant compounds, melatonin $[103,104]$ and the metalloporphyrin compound Mn (III) tetrakis (4-benzoic acid) porphyrin (MnTBAP) [105, 106] have been reported to be beneficial in SCI models in parallel with a reduction in PN-derived 3-NT levels in the injured spinal cord, suggesting that their overall protective effects are largely due to interference with PN oxidative damage. Although the decrease in $\mathrm{PN}$-induced nitrative damage (3NT) is no doubt therapeutically important, it must be noted that across all SCI studies carried out with various antioxidant compounds, the most consistent finding is a reduction in LP, as assessed by the levels of LP-derived products such as 4-HNE and/or acrolein. Moreover, recent work has shown that lipid peroxyl radicals (LOO•) play a key role in the chemical nitration of protein tyrosine residues by $\mathrm{PN}$-derived $\bullet \mathrm{NO}_{2}[107]$.

\section{Scavenging of neurotoxic lipid peroxidation-derived aldehydes in SCI models}

As previously discussed, 4-HNE and acrolein, which are derived from peroxidized polyunsaturated fatty acids provide useful markers of post-traumatic LP in the injured spinal cord. However, these 2 products have been repeatedly shown to be cytotoxic. For example, Hamann et al. $[25,108,109]$ have demonstrated that 4-HNE and acrolein are neurotoxic in SCI models, and that chemical scavenging of these toxic LP-derived aldehydes with certain hydrazinecontaining compounds that can covalently bind them is neuroprotective. The author's laboratory has also demonstrated that mitochondrial function is exquisitely sensitive to impairment by 4-HNE, and moreso to acrolein, and also that spinal cord mitochondria are 10-fold more sensitive than brain mitochondria [48].

\section{Efficacy of miscellaneous antioxidants in SCI models}

Further pharmacological validation of the neuroprotective benefits of inhibition of oxidative damage in the injured spinal cord is inicated by several compounds heretofore unmentioned, which have been reported to attenuate oxidative damage in SCI models. These include methylene blue [110], mexilitine [111], thiopental [112], 


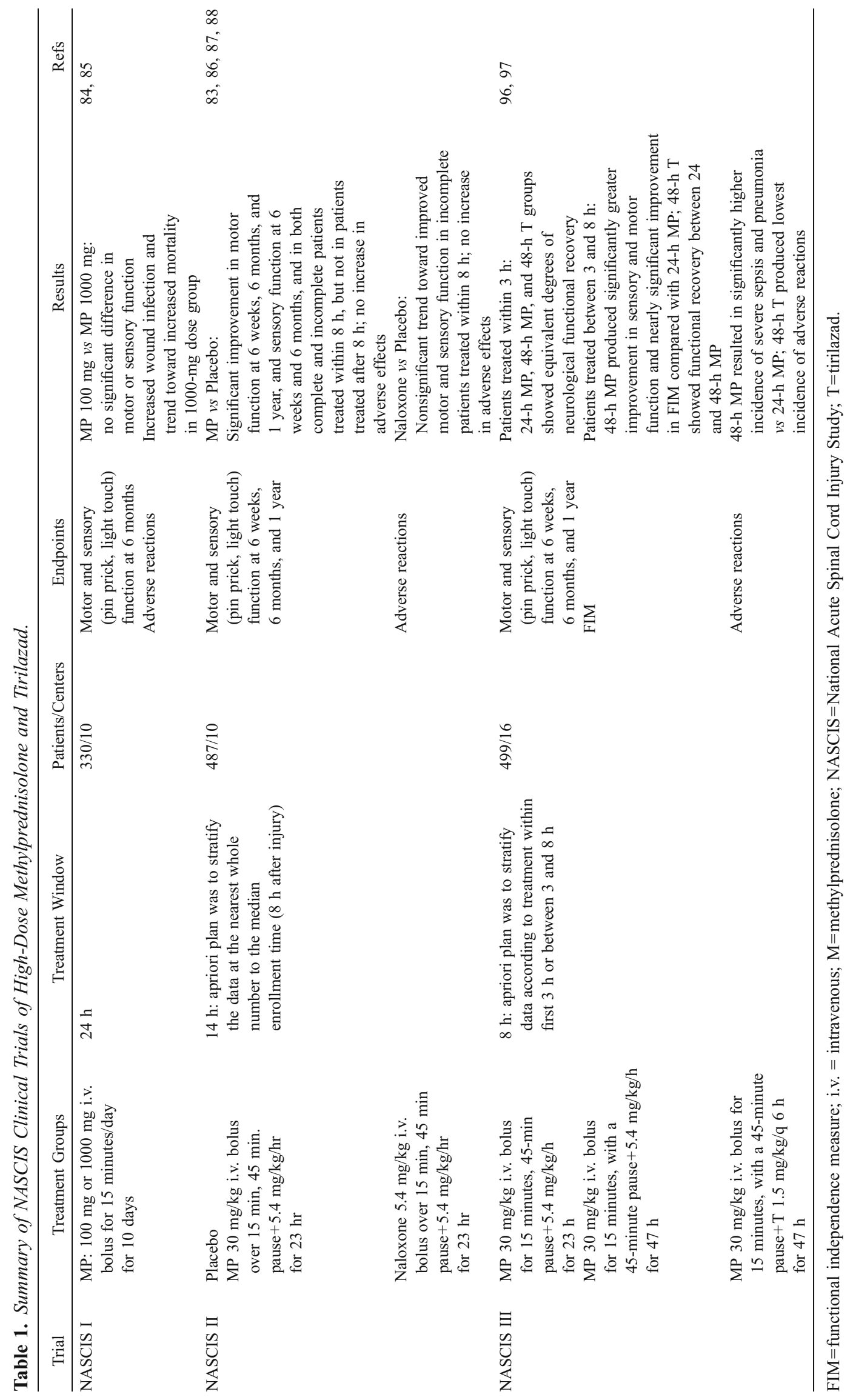



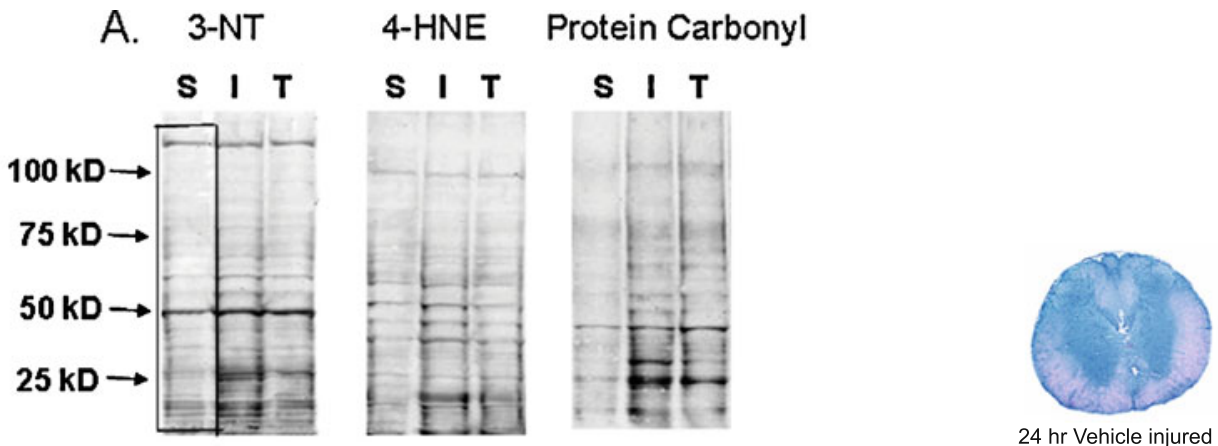

B.
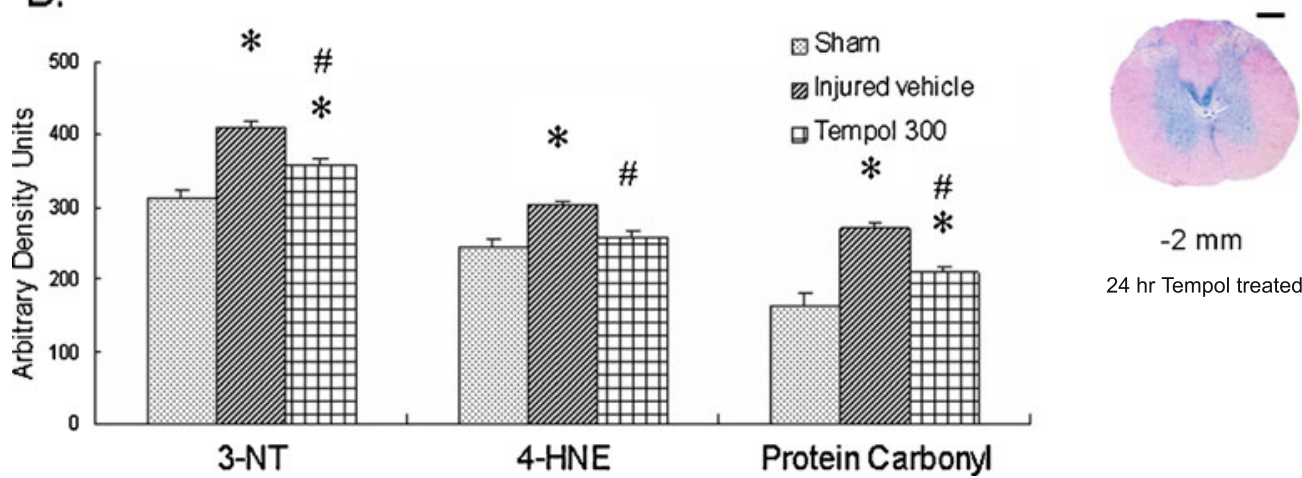

$24 \mathrm{hr}$ Tempol treated

FIG. 3. (a) Representative Western blots shows staining patterns of 3-nitrotyrosine (3-NT), 4-hydroxynonenal (4-HNE), and protein carbonyls. S, I, T=sham, vehicle, and tempol-treated groups (300 mg/kg, i.p.), respectively. Compared to the sham group, more intense staining patterns are observed in vehicle groups and tempol treatment attenuated the immunoreactivity. (b) Densitometric quantification of 3-NT, 4-HNE, and protein carbonyls (across various molecular weight ranges, included in the black box in each lane) showed significant injury-induced increases in peroxynitrite (PN) formation, lipid peroxidation and protein oxidation, which were each decreased by the $\mathrm{PN}$-derived radical scavenger tempol compared to the saline-treated injured group (values=mean \pm standard error; ${ }^{*} p<0.05$ vs sham; ${ }^{\#} p<$ 0.05 vs vehicle; $n=6$ /group). (c) Representative spinal cord cross sections $2 \mathrm{~mm}$ from the epicenter of the contusion injury from rats and treated with saline vehicle or tempol are shown Scale bar $=0.5 \mathrm{~mm}$. This figure is a collage of parts of FIGS. 2 and 3 , and for more detail see Xiong et al. [105], reproduced with permission.

$\beta$-glucan [113], N-acetylcysteine [114], $\gamma$-glutamylcysteine [18], polyethylene glycol [115], edaravone (MCI186), cyclosporine A [116], NIM811 [117, 118], erythropoietin [119] and $\alpha$-lipoic acid [120]. Although some of these are probably true chemical antioxidants (e.g., methylene blue, edaravone, $\alpha$-lipoic acid), others may work indirectly by induction of endogenous antioxidant defenses (e.g., N-acetylcysteine, $\gamma$-glutamylcysteine), reduction of mitochondrial dysfunction, and its associated free radical leakage (e.g., cyclosporine A, NIM811) or by enhancement of cell membrane repair mechanisms (e.g., polyethylene glycol). In the case of each of these miscellaneous antioxidants, further study is needed to define their relative neuroprotective efficacy in comparison to the other antioxidant approaches previously discussed.

\section{ANTIOXIDANT THERAPEUTIC WINDOW AND OPTIMAL TREATMENT DURATION IN SCI}

There are 2 key issues to consider regarding the feasibility of inhibiting oxidative damage in the acutely injured spinal cord. The first is the need to define the time of onset and the peak of free radical-induced oxidative damage, which should be predictive of the therapeutic time window for antioxidant therapy or how much time can pass before antioxidants lose their opportunity to exert a neuroprotective action. The second is the need to understand the post-traumatic duration of free radical formation and oxidative damage, which should predict the optimal treatment duration for antioxidant therapy.

\section{Onset and duration of oxidative damage in the injured spinal cord}

The author's laboratory was the first to define the onset of LP in a cat contusion SCI model in which it was shown that there is a significant increase in the levels of the LP breakdown product malondialdehyde (MDA) in the injured spinal tissue as early as 5 minutes post-injury, which continues to increase progressively during the first hour [121]. Increased levels of MDA were also seen in the contused rat spinal cord as early as 30 minutes post$\mathrm{SCI}$, which peaked at $3 \mathrm{~h}$ and returned to baseline by $12 \mathrm{~h}$ [26]. In a compression SCI model, MDA was significantly increased by 15 minutes, peaked at $1 \mathrm{~h}$ and 
then fell thereafter [122], suggesting that there is not much difference between the cat contusion and rat compression models at least as far as the onset of postSCI LP. However, two unfortunate limitations of these studies were the choice of MDA, which is a biomarker of enzymatic LP during the arachidonic acid cascade, as well as free radical-induced LP, and the fact that postinjury times longer than $12 \mathrm{~h}$ were not included. However, subsequent studies using one of the more contemporary rat contusion SCI paradigms and more sensitive immunoblotting of the immunohistochemical assay methods have more completely and specifically defined the time course of LP (4-HNE, acrolein) and protein oxidation (protein carbonyl), and nitration (3NT) following SCI. The first of these showed a peak increase in 4-HNE immunostaining at $24 \mathrm{~h}$ [21] or $48 \mathrm{~h}$ [20] after SCI. A more recent and more extended immunoblotting/immunohistochemical time course study in the rat contusion model has confirmed that the increase in 4-HNE occurs as early as $1 \mathrm{~h}$, peaks at $24 \mathrm{~h}$, and remains significantly elevated for at least 7 days [23]. However, 4-HNE immunohistochemical staining at 14 days after SCI reveals a persistent elevation [22]. The species or type of SCI model does not seem to make a difference, because in a guinea pig compression injury model the 4-HNE levels in injured spinal tissue also peaked at $24 \mathrm{~h}$ and persisted for at least 7 days [24].

Interestingly, the time course of PN-mediated 3-NT after rat contusion SCI mirrors the timing of LP-related 4-HNE levels in terms of early onset, peak at $24 \mathrm{~h}$, and persistence for at least 7 days, although by day 14 the 3NT immunostaining has waned much more than that for 4-HNE [22]. A re-examination of FIG. 2 reveals the spatial and temporal superimposition of 4-HNE and 3NT in the contused spinal cord at least out 7 days, which includes both microvascular and parenchymal elements. This strongly implies that much of the oxidative damage in that timeframe is produced by PN. In contrast, the longer persistence of the LP marker 4-HNE may be due to a later contribution of other inflammatory or ironcatalyzed free radical mechanisms, as previously discussed in this review. Alternatively, the persistence of 4HNE modified proteins may simply be due to their slower clearance via proteasomal degradation $v s$ the possibly faster repair of nitrated proteins by denitrase enzymes. Further study is needed to test these 2 possibilities. In any event, the oxidative time course studies collectively indicate that antioxidant treatment 1 ) needs to begin as soon as possible within the first hours after SCI; 2) needs to be optimally maintained for at least the first 24 to $48 \mathrm{~h}$ to cover the peak of spinal cord oxidative damage, and 3) may need to be maintained even longer if in fact the persistence of LP and protein nitrative damage out 7 to 14 days is demonstrated to represent ongoing oxidative damage, as opposed to simply the persistent presence of unrepaired oxidative damage that mainly transpired during the first 24 to $48 \mathrm{~h}$. Clearly, the present evidence suggests that treatment for at least the first $24 \mathrm{~h}$ is critically important because $24 \mathrm{~h}$ is also the time at which the peak of spinal cord mitochondrial oxidative damage and functional impairment occurs [28].

\section{Antioxidant therapeutic window and optimal treatment duration derived from the NASCIS trials}

As already mentioned, the NASCIS II clinical trial revealed that a 24-h high-dose MP regimen significantly improved motor functional recovery if initiated within the first $8 \mathrm{~h}$, but not if delayed until after that post-SCI time window [83, 86, 87]. If high-dose MP is exerting its neuroprotective effects by inhibition of LP, as theorized, then this indicates that $8 \mathrm{~h}$ is the therapeutic window in SCI. In subsequent studies in the cat spinal cord compression SCI model, the 21-aminosteroid tirilazad, which works solely by inhibiting LP, was shown to significantly improve motor functional recovery if a 48-h long treatment regimen was initiated within the first $4 \mathrm{~h}$, and the degree of recovery was just as great as when it was started within the first 30 minutes. Even after a delay of $8 \mathrm{~h}$, an improvement in recovery was still seen, although it did not quite reach statistical significance [95]. The similarity between the 8-h MP window defined in NASCIS II, and the similar window observed with tirilazad in the cat SCI model further supports the idea that the window for neuroprotection by an antioxidant mechanism in SCI is approximately 8 hours.

In the 3-arm NASCIS III clinical trial, which involved a comparison of 24-h MP vs either 48-h MP or 48-h tirilazad, it was shown that if treatment was initiated within the first 3 -h post-SCI, the neurological recoveries of the 3 treatment cohorts was statistically identical $[96,97]$. Thus, 24-h MP administration at a dose demonstrated repeatedly to inhibit post-traumatic LP in the injured cord was able to produce as much of an effect as 48-h antioxidant dosing, whether with high-dose MP or the selective antioxidant tirilazad. However, if treatment initiation was delayed until 3- to 8-h post$\mathrm{SCI}$, then extension of the MP treatment duration to $48 \mathrm{~h}$ resulted in a significantly higher degree of neurological recovery than if it was confined to only $24 \mathrm{~h}$. This latter observation indicates that a more delayed initiation of antioxidant administration until after the first $3 \mathrm{~h}$ after SCI necessitates a longer duration of antioxidant dosing to have an optimal effect. This is presumably due to the likelihood that the longer delay leads to a higher degree of free radical formation and LP chain reactions that would logically take a more aggressive dosing strategy to shut off. Nevertheless, the confirmation of this apparent 8-h antioxidant therapeutic window, the optimal treatment onset within the first few 
hours, the adequacy of a 24-treatment duration if this occurs, and the need for more prolonged dosing if drug administration does not begin until 3 to $8 \mathrm{~h}$, awaits further detailed preclinical study with newer, more potent and selective antioxidant drugs.

\section{CONCLUSIONS}

Free radical-induced oxidative damage is arguably one of the best-validated mechanisms involved in the complex secondary injury cascade, which occurs following acute SCI. Although free radical-mediated damage can occur in all types of biomolecules, LP appears to play a dominant role due to the high concentration of peroxidation-sensitive polyunsaturated fatty acids and high levels of the LP catalyst iron. Most convincingly, various LP inhibiting compounds and other antioxidants have been shown to be neuroprotective in acute SCI models. Two of these, high-dose MP and tirilazad have been shown in multi-center phase III SCI clinical trials (i.e., NASCIS II and III) to improve neurological recovery, albeit to a moderate degree. However, in the case of MP, the potential for glucocorticoid-related side effects has driven the continued search for safer and more effective antioxidant agents for acute SCI. One such mechanistic approach would be to scavenge PN or its derived free radicals that are critically involved in the postSCI oxidative damage. Second, there is increased interest in attempting to scavenge the neurotoxic aldehydic LP products 4-HNE and acrolein, which are key contributors to the overall effects of LP in the injured spinal cord. The available preclinical and clinical data indicate that antioxidant neuroprotection in acute SCI needs to be initiated within the first $8 \mathrm{~h}$, preferably within the first $3 \mathrm{~h}$, and that it should be continued for at least the first 24 to $48 \mathrm{~h}$. However, careful definition of the extended time course of post-traumatic LP and other forms of oxidative damage in the injured rat spinal cord far beyond the first $48 \mathrm{~h}$ may reflect a need for more prolonged antioxidant treatment after acute SCI, which is not feasible with high-dose MP and its associated side-effect profile. Accordingly, more potent and highly selective antioxidant compounds, which can simultaneously protect spinal cord microvessels (i.e., glia and neurons) are needed.

Acknowledgments: Full conflict of interest disclosure is available in the electronic supplementary material for this article. Some of the work reviewed in this aricle was supported by grants from the Kentucky Spinal Cord \& Head Injury Research Trust.

\section{REFERENCES}

1. Hall ED, Vaishnav RA, Mustafa AG. Antioxidant therapies for traumatic brain injury. Neurotherapeutics 2010;7:51-61.

2. Halliwell B, Gutteridge J. Free Radicals in Biology and Medicine, 3 rd ed. Oxford University Press, 2008.
3. Zaleska MM, Floyd RA. Regional lipid peroxidation in rat brain in vitro: possible role of endogenous iron. Neurochem Res 1985;10:397410.

4. Sadrzadeh SM, Graf E, Panter SS, Hallaway PE, Eaton JW. Hemoglobin: a biologic fenton reagent. J Biol Chem 1984;259:14354-14356.

5. Sadrzadeh SM, Eaton JW. Hemoglobin-mediated oxidant damage to the central nervous system requires endogenous ascorbate. J Clin Invest 1988;82:1510-1515.

6. Beckman JS. The double-edged role of nitric oxide in brain function and superoxide-mediated injury. J Dev Physiol 1991;15:53-59.

7. Anderson DK, Means ED, Waters TR, Spears CJ. Spinal cord energy metabolism following compression trauma to the feline spinal cord. J Neurosurg 1980;53:375-380.

8. Braughler JM, Hall ED. Lactate and pyruvate metabolism in injured cat spinal cord before and after a single large intravenous dose of methylprednisolone. J Neurosurg 1983;59:256-261.

9. Liu D, Sybert TE, Qian H, Liu J. Superoxide production after spinal injury detected by microperfusion of cytochrome c. Free Radic Biol Med 1998;25:298-304.

10. Bao F, Liu D. Hydroxyl radicals generated in the rat spinal cord at the level produced by impact injury induce cell death by necrosis and apoptosis: protection by a metalloporphyrin. Neuroscience 2004;126:285-295.

11. Anderson DK, Means ED. Iron-induced lipid peroxidation in spinal cord: protection with mannitol and methylprednisolone. J Free Radic Biol Med 1985;1:59-64.

12. Milvy P, Kakari S, Campbell JB, Demopoulos HB. Paramagnetic species and radical products in cat spinal cord. Ann N Y Acad Sci 1973;222:1102-1111.

13. Seligman ML, Flamm ES, Goldstein BD, Poser RG, Demopoulos HB, Ransohoff J. Spectrofluorescent detection of malonaldehyde as a measure of lipid free radical damage in response to ethanol potentiation of spinal cord trauma. Lipids 1977;12:945-950.

14. Hall ED, Braughler JM. Effects of intravenous methylprednisolone on spinal cord lipid peroxidation and $\mathrm{Na}++\mathrm{K}+$ )-ATPase activity. Dose-response analysis during 1st hour after contusion injury in the cat. J Neurosurg 1982;57:247-253.

15. Qian H, Liu D. The time course of malondialdehyde production following impact injury to rat spinal cord as measured by microdialysis and high pressure liquid chromatography. Neurochem Res 1997;22:1231-1236.

16. Pietronigro DD, Hovsepian M, Demopoulos HB, Flamm ES. Loss of ascorbic acid from injured feline spinal cord. $\mathrm{J}$ Neurochem 1983;41:1072-1076.

17. Hall ED, Yonkers PA, Andrus PK, Cox JW, Anderson DK. Biochemistry and pharmacology of lipid antioxidants in acute brain and spinal cord injury. J Neurotrauma 1992;(9 suppl 2):S425-S442.

18. Lucas JH, Wheeler DG, Guan Z, Suntres Z, Stokes BT. Effect of glutathione augmentation on lipid peroxidation after spinal cord injury. J Neurotrauma 2002;19:763-775.

19. Lemke M, Frei B, Ames BN, Faden AI. Decreases in tissue levels of ubiquinol-9 and -10, ascorbate and alpha-tocopherol following spinal cord impact trauma in rats. Neurosci Lett 1990;108:201206.

20. Baldwin SA, Broderick R, Osbourne D, Waeg G, Blades DA, Scheff SW. The presence of 4-hydroxynonenal/protein complex as an indicator of oxidative stress after experimental spinal cord contusion in a rat model. J Neurosurg 1998;88:874-883.

21. Springer JE, Azbill RD, Mark RJ, Begley JG, Waeg G, Mattson MP. 4-hydroxynonenal, a lipid peroxidation product, rapidly accumulates following traumatic spinal cord injury and inhibits glutamate uptake. J Neurochem 1997;68:2469-2476.

22. Carrico KM, Vaishnav R, Hall ED. Temporal and spatial dynamics of peroxynitrite-induced oxidative damage after spinal cord contusion injury. J Neurotrauma 2009;26:1369-1378.

23. Xiong Y, Rabchevsky AG, Hall ED. Role of peroxynitrite in secondary oxidative damage after spinal cord injury. J Neurochem 2007;100:639-649.

24. Luo J, Uchida K, Shi R. Accumulation of acrolein-protein adducts after traumatic spinal cord injury. Neurochem Res 2005;30:291295 . 
25. Hamann K, Durkes A, Ouyang H, Uchida K, Pond A, Shi R. Critical role of acrolein in secondary injury following ex vivo spinal cord trauma. J Neurochem 2008;107:712-721.

26. Liu JB, Tang TS, Xiao DS. Changes of free iron contents and its correlation with lipid peroxidation after experimental spinal cord injury. Chin J Traumatol 2004;7:229-232.

27. Aksenova M, Butterfield DA, Zhang SX, Underwood M, Geddes JW. Increased protein oxidation and decreased creatine kinase BB expression and activity after spinal cord contusion injury. J Neurotrauma 2002:19:491-502.

28. Sullivan PG, Krishnamurthy S, Patel SP, Pandya JD, Rabchevsky AG. Temporal characterization of mitochondrial bioenergetics after spinal cord injury. J Neurotrauma 2007;24:991-999.

29. Scott GS, Jakeman LB, Stokes BT, Szabo C. Peroxynitrite production and activation of poly (adenosine diphosphate-ribose) synthetase in spinal cord injury. Ann Neurol 1999;45:120-124.

30. $\mathrm{Xu}$ J, Gyeong-Moon $\mathrm{K}$, Chen $\mathrm{S}$, et al. iNOS and nitrotyrosine expression after spinal cord injury. J Neurotrauma 2001;18:523532.

31. Liu D, Ling X, Wen J, Liu J. The role of reactive nitrogen species in secondary spinal cord injury: formation of nitric oxide, peroxynitrite, and nitrated protein. J Neurochem 2000;75:2144-2154.

32. Bao F, DeWitt DS, Prough DS, Liu D. Peroxynitrite generated in the rat spinal cord induces oxidation and nitration of proteins: reduction by $\mathrm{Mn}$ (III) tetrakis (4-benzoic acid) porphyrin. J Neurosci Res 2003;71:220-227.

33. Bao F, Liu D. Peroxynitrite generated in the rat spinal cord induces neuron death and neurological deficits. Neuroscience 2002;115:839-849.

34. Bao F, Liu D. Peroxynitrite generated in the rat spinal cord induces apoptotic cell death and activates caspase-3. Neuroscience 2003; 116:59-70

35. Liu D, Bao F, Prough DS, Dewitt DS. Peroxynitrite generated at the level produced by spinal cord injury induces peroxidation of membrane phospholipids in normal rat cord: reduction by a metalloporphyrin. J Neurotrauma 2005;22:1123-1133.

36. Rohn TT, Hinds TR, Vincenzi FF. Ion transport ATPases as targets for free radical damage. Protection by an aminosteroid of the $\mathrm{Ca} 2+$ pump ATPase and $\mathrm{Na}+/ \mathrm{K}+$ pump ATPase of human red blood cell membranes. Biochem Pharmacol 1993;46:525-534.

37. Rohn TT, Hinds TR, Vincenzi FF. Inhibition of Ca2+-pump ATPase and the $\mathrm{Na}+/ \mathrm{K}+$-pump ATPase by iron-generated free radicals. Protection by 6,7-dimethyl-2,4-DI-1- pyrrolidinyl-7 Hpyrrolo[2,3-d] pyrimidine sulfate (U-89843D), a potent, novel, antioxidant/free radical scavenger. Biochem Pharmacol 1996;51:471-476.

38. Braughler JM, Duncan LA, Chase RL. Interaction of lipid peroxidation and calcium in the pathogenesis of neuronal injury. Cent Nerv Syst Trauma 1985;2:269-283

39. Clendenon NR, Allen N, Gordon WA, Bingham WG, Jr. Inhibition of $\mathrm{Na}+-\mathrm{K}+$-activated ATPase activity following experimental spinal cord trauma. J Neurosurg 1978;49:563-568.

40. Azbill RD, Mu X, Bruce-Keller AJ, Mattson MP, Springer JE. Impaired mitochondrial function, oxidative stress and altered antioxidant enzyme activities following traumatic spinal cord injury. Brain Res 1997;765:283-290.

41. Sullivan PG, Thompson MB, Scheff SW. Cyclosporin A attenuates acute mitochondrial dysfunction following traumatic brain injury. Exp Neurol 1999;160:226-234

42. Sullivan PG, Bruce-Keller AJ, Rabchevsky AG, et al. Exacerbation of damage and altered NF-kappaB activation in mice lacking tumor necrosis factor receptors after traumatic brain injury. J Neurosci 1999; 19:6248-6256

43. Matsushita M, Xiong G. Projections from the cervical enlargement to the cerebellar nuclei in the rat, studied by anterograde axonal tracing. J Comp Neurol 1997;377:251-261.

44. Lopez-Figueroa MO, Caamano C, Morano MI, Ronn LC, Akil H, Watson SJ. Direct evidence of nitric oxide presence within mitochondria. Biochem Biophys Res Commun 2000;272:129-133.

45. Zanella B, Calonghi N, Pagnotta E, Masotti L, Guarnieri C. Mitochondrial nitric oxide localization in $\mathrm{H} 9 \mathrm{c} 2$ cells revealed by confocal microscopy. Biochem Biophys Res Commun 2002;290:1010-1014.
46. Bringold U, Ghafourifar P, Richter C. Peroxynitrite formed by mitochondrial $\mathrm{NO}$ synthase promotes mitochondrial $\mathrm{Ca} 2+$ release. Free Radic Biol Med 2000;29:343-348.

47. Valdez LB, Alvarez S, Arnaiz SL, et al. Reactions of peroxynitrite in the mitochondrial matrix. Free Radic Biol Med 2000;29:349356.

48. Vaishnav RA, Singh IN, Miller DM, Hall ED. Lipid peroxidationderived reactive aldehydes directly and differentially impair spinal cord and brain mitochondrial function. J Neurotrauma 2010;27:1311-1320

49. Park E, Velumian AA, Fehlings MG. The role of excitotoxicity in secondary mechanisms of spinal cord injury: a review with an emphasis on the implications for white matter degeneration. J Neurotrauma 2004;21:754-774

50. Xu GY, Hughes MG, Ye Z, Hulsebosch CE, McAdoo DJ Concentrations of glutamate released following spinal cord injury kill oligodendrocytes in the spinal cord. Exp Neurol 2004;187:329336.

51. Stys PK. White matter injury mechanisms. Curr Mol Med 2004;4:113-130.

52. Alessandri B, Bullock R. Glutamate and its receptors in the pathophysiology of brain and spinal cord injuries. Prog Brain Res 1998;116:303-330.

53. Pellegrini-Giampietro DE, Cherici G, Alesiani M, Carla V, Moroni F. Excitatory amino acid release and free radical formation may cooperate in the genesis of ischemia-induced neuronal damage. J Neurosci 1990;10:1035-1041

54. Braughler JM. Lipid peroxidation-induced inhibition of gammaaminobutyric acid uptake in rat brain synaptosomes: protection by glucocorticoids. J Neurochem 1985;44:1282-1288.

55. Zhang JR, Scherch HM, Hall ED. Direct measurement of lipid hydroperoxides in iron-dependent spinal neuronal injury. J Neurochem 1996;66:355-361.

56. Monyer H, Hartley DM, Choi DW. 21-Aminosteroids attenuate excitotoxic neuronal injury in cortical cell cultures. Neuron 1990;5:121-126.

57. Demopoulos HB, Flamm ES, Pietronigro DD, Seligman ML. The free radical pathology and the microcirculation in the major central nervous system disorders. Acta Physiol Scand Suppl 1980;492:91119.

58. Hall ED, Wolf DL. A pharmacological analysis of the pathophysiological mechanisms of posttraumatic spinal cord ischemia. J Neurosurg 1986;64:951-961.

59. Hall ED, Wolf DL, Braughler JM. Effects of a single large dose of methylprednisolone sodium succinate on experimental posttraumatic spinal cord ischemia. Dose-response and time-action analysis. J Neurosurg 1984;61:124-130.

60. Hall ED. Effects of the 21-aminosteroid U74006F on posttraumatic spinal cord ischemia in cats. J Neurosurg 1988;68:462-465.

61. Hummel SG, Fischer AJ, Martin SM, Schafer FQ, Buettner GR. Nitric oxide as a cellular antioxidant: a little goes a long way. Free Radic Biol Med 2006;40:501-506.

62. Carroll RT, Galatsis P, Borosky S, et al. 4-Hydroxy-2,2,6,6tetramethylpiperidine-1-oxyl (Tempol) inhibits peroxynitrite-mediated phenol nitration. Chem Res Toxicol 2000;13:294-300.

63. Liu D, McAdoo DJ. Methylprednisolone reduces excitatory amino acid release following experimental spinal cord injury. Brain Res 1993;609:293-297.

64. Anderson DK, Saunders RD, Demediuk P, et al. Lipid hydrolysis and peroxidation in injured spinal cord: partial protection with methylprednisolone or vitamin E and selenium. Cent Nerv Syst Trauma 1985;2:257-267.

65. Hall ED, Yonkers PA, Horan KL, Braughler JM. Correlation between attenuation of posttraumatic spinal cord ischemia and preservation of tissue vitamin E by the 21-aminosteroid U74006F: evidence for an in vivo antioxidant mechanism. J Neurotrauma 1989;6:169-176

66. Anderson DK, Waters TR, Means ED. Pretreatment with alpha tocopherol enhances neurologic recovery after experimental spinal cord compression injury. J Neurotrauma 1988;5:61-67.

67. Iwasa K, Ikata T, Fukuzawa K. Protective effect of vitamin E on spinal cord injury by compression and concurrent lipid peroxidation. Free Radic Biol Med 1989;6:599-606. 
68. Taoka Y, Ikata T, Fukuzawa K. Influence of dietary vitamin E deficiency on compression injury of rat spinal cord. J Nutr Sci Vitaminol (Tokyo) 1990;36:217-226.

69. Machlin L, Gabriel E. Kinetics of tissue alpha tocopherol uptake and depletion following administration of high levels of vitamin $\mathrm{E}$. Ann N Y Acad Sci 1982;393:48-59.

70. Roberts LJ, 2nd, Oates JA, Linton MF, et al. The relationship between dose of vitamin $\mathrm{E}$ and suppression of oxidative stress in humans. Free Radic Biol Med 2007;43:1388-1393.

71. Demopoulos HB, Flamm ES, Seligman ML, Pietronigro DD, Tomasula J, DeCrescito V. Further studies on free-radical pathology in the major central nervous system disorders: effect of very high doses of methylprednisolone on the functional outcome, morphology, and chemistry of experimental spinal cord impact injury. Can J Physiol Pharmacol 1982;60:1415-1424.

72. Hall ED. The neuroprotective pharmacology of methylprednisolone. J Neurosurg 1992;76:13-22.

73. Hall ED, Braughler JM. Acute effects of intravenous glucocorticoid pretreatment on the in vitro peroxidation of cat spinal cord tissue. Exp Neurol 1981;73:321-324.

74. Hall ED, Braughler JM. Glucocorticoid mechanisms in acute spinal cord injury: a review and therapeutic rationale. Surg Neurol 1982;18:320-327.

75. Young W, Flamm ES. Effect of high-dose corticosteroid therapy on blood flow, evoked potentials, and extracellular calcium in experimental spinal injury. J Neurosurg 1982;57:667-673.

76. Anderson DK, Means ED, Waters TR, Green ES. Microvascular perfusion and metabolism in injured spinal cord after methylprednisolone treatment. J Neurosurg 1982;56:106-113.

77. Braughler JM, Hall ED. Effects of multi-dose methylprednisolone sodium succinate administration on injured cat spinal cord neurofilament degradation and energy metabolism. J Neurosurg 1984;61:290-295.

78. Braughler JM, Hall ED. Correlation of methylprednisolone levels in cat spinal cord with its effects on $(\mathrm{Na}++\mathrm{K}+)$-ATPase, lipid peroxidation, and alpha motor neuron function. $\mathrm{J}$ Neurosurg 1982;56:838-844.

79. Braughler JM, Hall ED. Uptake and elimination of methylprednisolone from contused cat spinal cord following intravenous injection of the sodium succinate ester. J Neurosurg 1983;58:538-542.

80. Braughler JM, Hall ED, Means ED, Waters TR, Anderson DK. Evaluation of an intensive methylprednisolone sodium succinate dosing regimen in experimental spinal cord injury. J Neurosurg 1987;67:102-105.

81. Lee J-M, Yang, P, Xiao, Q, Chen, S, Lee, K-Y, Hsu, CY, Xu, J. Methyprednisolone protects oligodendrocytes but not neurons after spinal cord injury. J Neurosci 2008;28:3141-3149.

82. Hall ED, Springer JE. Neuroprotection and acute spinal cord injury: a reappraisal. NeuroRx 2004;1:80-100.

83. Bracken MB, Shepard MJ, Collins WF, et al. A randomized, controlled trial of methylprednisolone or naloxone in the treatment of acute spinal-cord injury. Results of the Second National Acute Spinal Cord Injury Study. N Engl J Med 1990;322:1405-1411.

84. Bracken MB, Shepard MJ, Hellenbrand KG, et al. Methylprednisolone and neurological function 1 year after spinal cord injury. Results of the National Acute Spinal Cord Injury Study. J Neurosurg 1985;63:704-713.

85. Bracken MB, Collins WF, Freeman DF, et al. Efficacy of methylprednisolone in acute spinal cord injury. JAMA 1984;251:45-52.

86. Bracken MB, Shepard MJ, Collins WF, Jr., et al. Methylprednisolone or naloxone treatment after acute spinal cord injury: 1-year follow-up data. Results of the second National Acute Spinal Cord Injury Study. J Neurosurg 1992;76:23-31.

87. Bracken MB, Holford TR. Effects of timing of methylprednisolone or naloxone administration on recovery of segmental and long-tract neurological function in NASCIS 2. J Neurosurg 1993;79:500-507.

88. Bracken MB. Pharmacological treatment of acute spinal cord injury: current status and future projects. J Emerg Med 1993;(11 suppl 1):43-48.

89. Otani K AH, Kadoya S. Beneficial effect of methylprednisolone sodium succinate in the treatment of acute spinal cord injury. Sekitsui Sekizui (in Japanese) 1994;7:633-647.

90. Petitjean ME, Pointillart, V, Dixmerias F. Medical treatment of spinal cord injury in the acute stage. Ann Fr Anesth Reanim (in French) $1998 ; 17: 114-122$.
91. Hall ED. Lazaroid: mechanisms of action and implications for disorders of the CNS. The Neuroscientist 1997;3:42-51.

92. Hall ED, McCall JM, Means ED. Therapeutic potential of the lazaroids (21-aminosteroids) in acute central nervous system trauma, ischemia and subarachnoid hemorrhage. Adv Pharmacol 1994;28:221-268.

93. Braughler JM, Chase RL, Neff GL, et al. A new 21-aminosteroid antioxidant lacking glucocorticoid activity stimulates adrenocorticotropin secretion and blocks arachidonic acid release from mouse pituitary tumor (AtT-20) cells. J Pharmacol Exp Ther 1988;244:423-427.

94. Anderson DK, Braughler JM, Hall ED, Waters TR, McCall JM, Means ED. Effects of treatment with U-74006 F on neurological outcome following experimental spinal cord injury. J Neurosurg 1988;69:562-567.

95. Anderson DK, Hall ED, Braughler JM, McCall JM, Means ED. Effect of delayed administration of U74006F (tirilazad mesylate) on recovery of locomotor function after experimental spinal cord injury. J Neurotrauma 1991;8:187-192.

96. Bracken MB, Shepard MJ, Holford TR, et al. Administration of methylprednisolone for 24 or 48 hours or tirilazad mesylate for 48 hours in the treatment of acute spinal cord injury. Results of the Third National Acute Spinal Cord Injury Randomized Controlled Trial. National Acute Spinal Cord Injury Study. JAMA 1997;277:1597-1604.

97. Bracken MB, Shepard MJ, Holford TR, et al. Methylprednisolone or tirilazad mesylate administration after acute spinal cord injury: 1-year follow up. Results of the third National Acute Spinal Cord Injury randomized controlled trial. J Neurosurg 1998;89:699-706.

98. Scott GS, Cuzzocrea S, Genovese T, Koprowski H, Hooper DC. Uric acid protects against secondary damage after spinal cord injury. Proc Natl Acad Sci U S A 2005;102:3483-3488.

99. Genovese T, Mazzon E, Esposito E, et al. Beneficial effects of FeTSPP, a peroxynitrite decomposition catalyst, in a mouse model of spinal cord injury. Free Radic Biol Med 2007;43:763780 .

100. Hillard VH, Peng H, Zhang Y, et al. Tempol, a nitroxide antioxidant, improves locomotor and histological outcomes after spinal cord contusion in rats. J Neurotrauma 2004;21:1405-1414.

101. Xiong Y, Hall ED. Pharmacological evidence for a role of peroxynitrite in the pathophysiology of spinal cord injury. Exp Neurol 2009;216:105-114.

102. Xiong Y, Singh IN, Hall ED. Tempol protection of spinal cord mitochondria from peroxynitrite-induced oxidative damage. Free Radic Res 2009;43:604-612.

103. Liu JB, Tang TS, Yang HL, Xiao DS. Antioxidation of melatonin against spinal cord injury in rats. Chin Med J (Engl) 2004;117:571-575.

104. Genovese T, Mazzon E, Muia C, Bramanti P, De Sarro A, Cuzzocrea S. Attenuation in the evolution of experimental spinal cord trauma by treatment with melatonin. J Pineal Res 2005;38:198-208.

105. Hachmeister JE, Valluru L, Bao F, Liu D. Mn (III) tetrakis (4benzoic acid) porphyrin administered into the intrathecal space reduces oxidative damage and neuron death after spinal cord injury: a comparison with methylprednisolone. J Neurotrauma 2006;23:1766-1778.

106. Ling X, Liu D. Temporal and spatial profiles of cell loss after spinal cord injury: Reduction by a metalloporphyrin. J Neurosci Res 2007;85:2175-2185.

107. Mustafa AG, Singh IN, Wang J, Carrico KM, Hall ED. Mitochondrial protection after traumatic brain injury by scavenging lipid peroxyl radicals. J Neurochem 2010;114:271280.

108. Hamann K, Nehrt G, Ouyang H, Duerstock B, Shi R. Hydralazine inhibits compression and acrolein-mediated injuries in ex vivo spinal cord. J Neurochem 2008;104:708-718.

109. Hamann K, Shi R. Acrolein scavenging: a potential novel mechanism of attenuating oxidative stress following spinal cord injury. J Neurochem 2009;111:1348-1356.

110. Bardakci H, Kaplan S, Karadeniz U, et al. Methylene blue decreases ischemia-reperfusion (I/R)-induced spinal cord injury: 
an in vivo study in an I/R rabbit model. Eur Surg Res 2006;38: 482-488.

111. Kaptanoglu E, Caner HH, Surucu HS, Akbiyik F. Effect of mexiletine on lipid peroxidation and early ultrastructural findings in experimental spinal cord injury. J Neurosurg 1999;91:200-204.

112. Kaptanoglu E, Sen S, Beskonakli E, et al. Antioxidant actions and early ultrastructural findings of thiopental and propofol in experimental spinal cord injury. J Neurosurg Anesthesiol 2002;14:114-122.

113. Kayali H, Ozdag MF, Kahraman S, et al. The antioxidant effect of beta-Glucan on oxidative stress status in experimental spinal cord injury in rats. Neurosurg Rev 2005;28:298-302.

114. Kaynar MY, Erdincler P, Tadayyon E, Belce A, Gumustas K, Ciplak N. Effect of nimodipine and $\mathrm{N}$-acetylcysteine on lipid peroxidation after experimental spinal cord injury. Neurosurg Rev 1998;21:260-264.

115. Luo J, Borgens R, Shi R. Polyethylene glycol immediately repairs neuronal membranes and inhibits free radical production after acute spinal cord injury. J Neurochem 2002;83:471-480.

116. Diaz-Ruiz A, Rios C, Duarte I, et al. Cyclosporin-A inhibits lipid peroxidation after spinal cord injury in rats. Neurosci Lett 1999;266:61-64.
117. McEwen ML, Sullivan PG, Springer JE. Pretreatment with the cyclosporin derivative, NIM811, improves the function of synaptic mitochondria following spinal cord contusion in rats. J Neurotrauma 2007;24:613-624.

118. Ravikumar R, McEwen ML, Springer JE. Post-treatment with the cyclosporin derivative, NIM811, reduced indices of cell death and increased the volume of spared tissue in the acute period following spinal cord contusion. J Neurotrauma 2007;24:1618-1630.

119. Yazihan N, Uzuner K, Salman B, Vural M, Koken T, Arslantas A. Erythropoietin improves oxidative stress following spinal cord trauma in rats. Injury 2008;39:1408-1413.

120. Toklu HZ, Hakan T, Celik H, et al. Neuroprotective effects of alpha-lipoic acid in experimental spinal cord injury in rats. J Spinal Cord Med;33:401-409.

121. Hall ED, Braughler JM. Free radicals in CNS injury. Res Publ Assoc Res Nerv Ment Dis 1993;71:81-105.

122. Barut S, Canbolat A, Bilge T, Aydin Y, Cokneseli B, Kaya U. Lipid peroxidation in experimental spinal cord injury: time-level relationship. Neurosurg Rev 1993;16:53-59. 